\title{
Morphometric Investigation of Neurons in the Hippocampal CA1, CA3 Areas and Dentate Gyrus in a Rat Model of Sepsis
}

\author{
Investigación Morfométrica de Neuronas en las Áreas Hipocampales \\ CA1, CA3 y Giro Dentado en un Modelo de Sepsis en Rata
}

Ilker M. Kafa; Ilknur Ari \& M. Ayberk Kurt

\begin{abstract}
KAFA, I. M.; ARI, I. \& KURT, M. A. Morphometric investigation of neurons in the hippocampal CA1, CA3 areas and dentate gyrus in a rat model of sepsis. Int. J. Morphol., 28(1):183-192, 2010.

SUMMARY: Approximately, half of the patients with progressive sepsis develop encephalopathy, but there is scarce knowledge onto question that how the sepsis associated encephalopathy contributes brain dysfunction. Hippocampus is one of the most vulnerable regions during experimental sepsis. In the present study, effects of sepsis on the neuronal density and morphology in CA1, CA3 and DG areas were investigated in a rat model of intraperitoneal sepsis. Twenty-four Wistar rats were divided into three different groups: faecal peritonitis group, sham-operated and un-operated control groups. Pyramidal neuron volume density was significantly higher in CA1 area of the faecal peritonitis group compared to both un-operated $(p<0.05)$ and sham-operated $(p<0.05)$ groups. Pyramidal neuron volume density was also significantly higher in CA3 area of the faecal peritonitis group compared to both un-operated $(p<0.05)$ and shamoperated $(p<0.05)$ groups. Mean nuclear diameter of pyramidal neurons in CA1 area of the faecal peritonitis group was significantly lower $(p<0.05)$ compared to un-operated control group. Dark, shrunken neurons were frequently observed and neuroglial cells appeared to be prevalent in the faecal peritonitis group compared to control groups. These results collectively suggest that intraperitoneal sepsis does not initiate cell death in the early stages of sepsis, although morphological signs of neurodegeneration start to appear.
\end{abstract}

KEY WORDS: Sepsis; Animal models of sepsis; Faecal peritonitis; Hippocampus; Sepsis associated encephalopathy.

\section{INTRODUCTION}

Despite the consequences of the challenging research for many years and encouraging advances in various therapeutic alternatives, sepsis and septic shock still constitutes one of the major causes of death in intensive care units (Papadopoulos et al., 2000). Sepsis and septic shock is the intersection between infection, inflammation and severe organ dysfunction, which are both previously defined by a set of agreed criteria (American College of Chest Physicians/ Society of Critical Care Medicine Consensus Conference, 1992). They occur as a complication of at least 50-60\% of gram-negative bacteremias and 5-10\% of gram-positive or fungal bloodstream infections for many years (Parrillo et al., 1990) and are associated with widespread endothelial cell damage, caused by persistent, uncontrolled inflammation (Bone, 1992; Papadopoulos et al., 1999). However, gram positive infections have increased in the past two decades and now account for about half of cases of severe sepsis (Bochud \& Calandra, 2003). Damage to the vascular endothelium caused by different infectious agents, triggers the release of a variety of mediators of inflammation and this uncontrolled inflammation causes the deposition of fibrin and the formation of thrombin within the microvessels (Bradley et al., 1994). As a result, insufficient regional blood flow frequently occurs in organs and progressive end organ dysfunctions may develop (Parrillo et al.; Voyce \& Becker, 1991; Deng et al., 1995).

Sepsis associated encephalopathy (SAE), which has been reported as a poor prognostic factor, develops in $8 \%$ to $70 \%$ of patients with progressive systemic sepsis (Papadopoulos et al., 2000; Wilson \& Young, 2003). It is well established that patients with severe sepsis often manifest an encephalopathy of variable severity and it is associated with significantly increased mortality (Bogdanski et al., 1999; Papadopoulos et al., 2000; Eggers et al., 2003). Although ample amount of attention has been given to the 
immunological and biochemical mechanisms involved in SAE, little is known about the morphological changes that occurs during the disease (Papadopoulos et al., 2000). SAE has been associated with disturbances of the cerebral microcirculation and blood-brain barrier (BBB) breakdown (Davies, 2002), since patients with SAE have been shown to contain increased protein levels in the cerebrospinal fluid (Basler et al., 2002), and various neutral amino acids (Jeppson et al., 1981), colloidal iron oxide (Clawson et al., 1966), dyes and tracers such as horseradish peroxidase (Moulin et al., 1985), evans blue (Esen et al., 2005) and macromolecules such as E. coli M4 (Tsao et al., 2001) have been shown to pass from the circulation into the brain parenchyma in rodent models of sepsis. Papadopoulos et al. (1999; 2000) have reported that occasionally extravasated, swollen and more spherical erythrocytes, swollen astrocyte end-feet and dark, shrunken neurons with pyknotic nuclei together with perimicrovascular oedema in the frontal cortex of a pig model of sepsis. Finally, we have recently demonstrated the presence of significant perimicrovascular oedema together with tight junctions, which appeared morphologically intact in the frontal cortex and CA1 area of hippocampus of a rat model of sepsis (Ari et al., 2006; Kafa et al., 2007). These observations suggest that neurodegenerative changes do occur in septic brain and hippocampus has been postulated as the most vulnerable region compared to other brain regions during experimental sepsis (Semmler et al., 2005). Thus, in an effort to examine the possible effects of sepsis on hippocampal formation, an investigation has been performed in CA1, CA3 and dentate gyrus (DG) areas of a rat model of sepsis in the present study.

\section{MATERIAL AND METHOD}

Animals. Twenty-four male, adult Wistar rats weighing 240$290 \mathrm{~g}$ were used in this study. Rats were obtained from the Experimental Animals Breeding and Research Centre of Uludag University Medical Faculty and experimental protocols have been approved by the Animal Care and Use Committee of the Uludag University. The rats were housed four per cage at $20-24^{\circ} \mathrm{C}$ under a $12: 12 \mathrm{~h}$ light:dark regime and received standard laboratory chow and tap water $a d$ libitum.

Experimental protocol. Rats were prepared for surgery under anesthesia with intraperitoneal urethane $(1.25 \mathrm{~g} / \mathrm{kg})$ and blood pressure, heart rate, respiration rate and rectal temperature were monitored as described in our previous study (Ari et al.) in order to confirm the adequate induction of sepsis. Rats were randomized into three groups, in the experiment group A, faecal peritonitis was induced in a to- tal of eight rats by intraperitoneal administration of a pooled faecal inoculum in order to ensure a uniform inoculation of micro-organisms to all animals (Lang et al., 1983; 1984). After anesthesia approximately one $\mathrm{cm}$ long midline incision was made on the anterior abdominal wall, $10 \mathrm{ml} / \mathrm{kg}$ of a pooled faecal suspension derived from several animals was withdrawn into a syringe ( $1: 4 \mathrm{w} / \mathrm{v}$ in sterile saline $)$ and spread evenly throughout the peritoneum to induce peritonitis. Faecal suspension was incubated at room temperature for 30 min before spreading around the peritoneum and also inoculated onto an agar plate for screening of specimens for coliforms. The incision was then closed in an aseptic surgical manner, the abdomen gently massaged to distribute the suspension and vital functions were monitored and recorded for $4 \mathrm{~h}$, before the animals were sacrificed by decapitation and their brains were removed. In the sham-operated group (Group B, $n=8$ ), a sham procedure was carried out in which a laparotomy was performed but only sterile saline $(10 \mathrm{ml} /$ $\mathrm{kg}$ ) was spread around the peritoneum and the incision then closed. Finally, brains of un-operated control group (Group $\mathrm{C}, \mathrm{n}=8$ ) were also removed for morphometric comparisons.

Tissue removal and processing. Immediately after decapitation, the brains were removed and immersed over night in $4 \%$ paraformaldehyde, $0.5 \%$ glutaraldehyde in 0.2 $\mathrm{M}$ phosphate buffer, $\mathrm{pH} 7.4$ at room temperature. The two cerebral hemispheres first divided sagittally, the right hemispheres of each brain were then cut transversely just anterior to the splenium (Bregma $-4.30 \mathrm{~mm}$ ) and $1 \mathrm{~mm}$ thick coronal slices were taken parallel to the cut surface of the anterior half of the right hemisphere throughout the entire hippocampus. Each slice was then trimmed to produce two rectangular blocks of tissue extending across hippocampus that containing CA1 and DG in the first and CA3 in the second. Tissue blocks were immersed into the similar fixative for an additional $1 \mathrm{~h}$. The tissues were then rinsed in phosphate buffer and post-fixed with $1 \%$ osmium tetroxide in $0.2 \mathrm{M}$ phosphate buffer for $2 \mathrm{~h}$. They were then rewashed in phosphate buffer, dehydrated through graded series of alcohols and processed into Spur's resin (Agar Scientific Ltd, Stansted, Essex, U.K.). Finally, the tissue blocks were coded so that subsequent analysis could be performed 'blind'.

Estimation on neuron volume density. Semi-thin sections $(0.5 \mu \mathrm{m})$ of the embedded tissue were cut, picked up on glass slides, and stained with a mixture of $1 \%$ toluidine blue and $1 \%$ boric acid in distilled water. A Sony DSC-F717 digital camera attached to a Nikon 4S-2 Alphaphot light microscope and PC running Scion-Image software (public domain, version 4.02) were used to capture images and to carry out the measurements. The image analysis system was calibrated using a stage micrometer prior to all measurements performed. The unfolding systematic random sampling 
procedure (Miki et al., 1997) was then carried out on randomly selected tissue blocks from each animal. A total of 15 images were captured for each hippocampal field per animal (five images per field $\mathrm{X}$ three tissue blocks). A counting frame of known area $(43.85 \times 40.85 \mu \mathrm{m})$ was then created using ScionImage software and superimposed on the digital image to be counted and measured, after the appropriate calibrations. Neuronal nuclei were selected as the counting unit and distinguished from glial nuclei by their morphological features and staining patterns (Ling et al., 1973). They were quantified according to the forbidden line rule (Miki et al.), in which the neuronal nuclei within the counting frame and those touching its upper and right margins were counted. The perimeters of nuclei of neurons that contain a distinctive nucleolus were outlined using Scion Image's tracing feature in order to obtain mean neuronal nucleus diameters as illustrated in Fig. 1. The volume densities of neurons $\left(\mathrm{Nv}_{\mathrm{n}}\right)$ were then estimated by applying the formula: $\mathrm{Nv}_{\mathrm{n}}=\mathrm{Na}_{\mathrm{n}} /\left(\overline{\mathrm{D}}_{\mathrm{n}}+\mathrm{t}\right)$ where is the number of neurons per unit area, $\overline{\mathrm{Dn}}$ is the mean nuclear diameter and $t$ is the section thickness.

Statistics. For the statistical analysis of the morphometric data, the mean values and standard error of means (SEM) were first estimated and One Way Analysis of Variance test were used to compare the morphometric data in the CA1, CA3 and DG areas. A probability of $\mathrm{p}<0.05$ considered significant for all statistical comparisons (Sigma-Stat, ver.3.0: Sigma-Plot, ver.4.0).

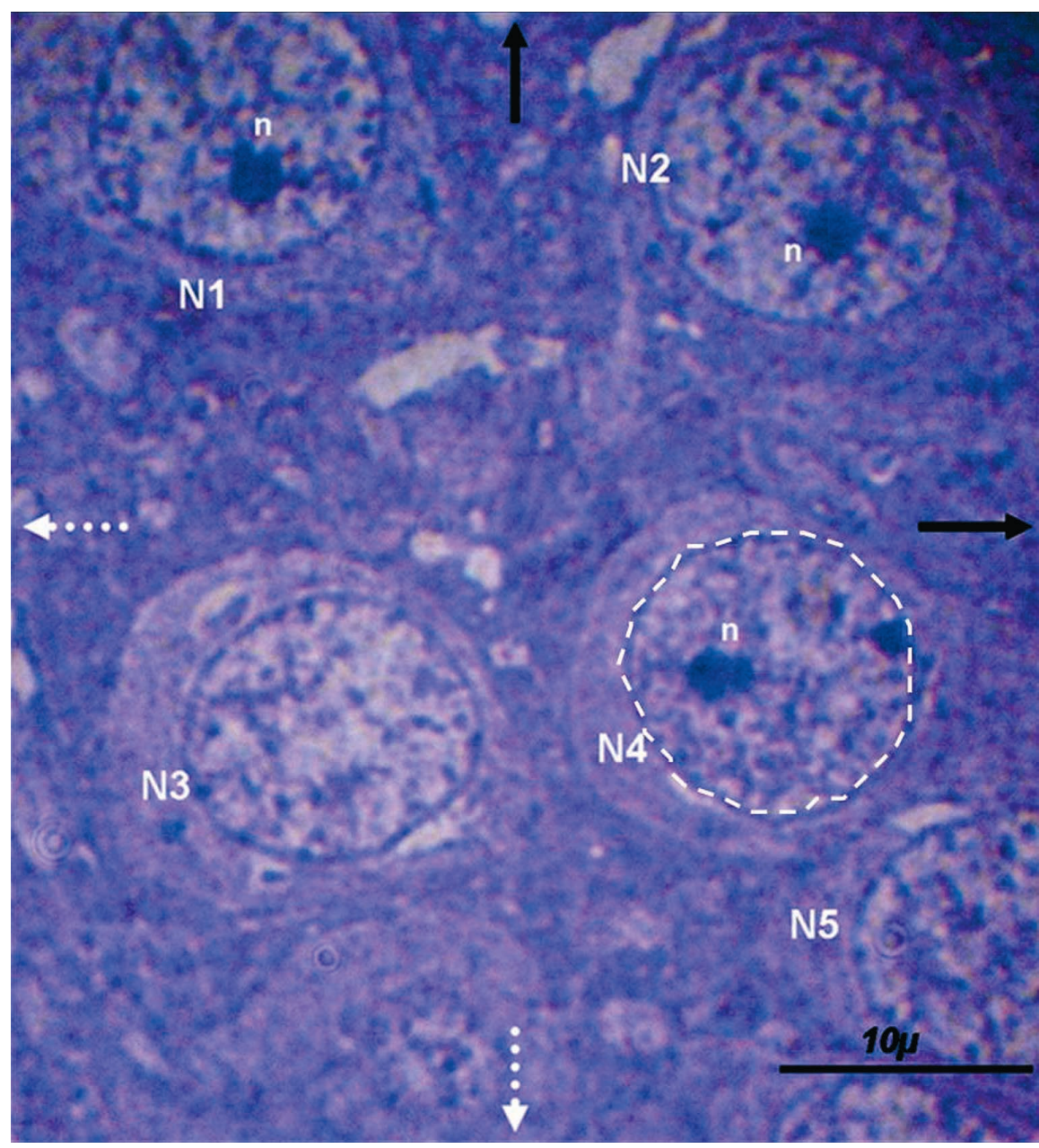

Fig. 1. A photomicrograph of a toulidine blue-stained semi-thin section from the stratum pyramidale of CA1 of rat from a faecal peritonitis group to show the estimation of neuron volume density. Neuronal nuclei were used as the counting unit and could be distinguished from those of glia by their morphological features. Neuronal nuclei, which crossed the upper and right margins or inside of the counting frame (thick lines and black arrows), were counted (N1-5), whereas those, which crossed the lower and left borders of the counting frame (thin lines and white arrows), were not counted. The diameters of neuronal nuclei were estimated from measurements of their circumference within the neurons that have nucleolus (n) (N1-2 and N4). Scale bar "10 $10 \mathrm{~m}$ ".

\section{RESULTS}

In line with our previous studies (Ari et al.; Kafa et al.), vital parameters obtained from the faecal peritonitis group revealed a marked drop in the blood pressure and in rectal temperature $(81.3 \%$ and $83 \%$, respectively), while an upward tendency in heart rate and a pronounced respiratory failure $(81 \%$ decrease in respiratory rate) were recorded at 4 hour after the induction of sepsis. Two-way ANOVA shows significantly difference between faecal peritonitis group and sham operated group for all vital parameters $(p<0.01)$. Qualitative investigation of the tissues revealed that the morphological preservation of the tissue was good and there were no obvious sign of micro abscesses and artifacts in all three groups investigated. Dark, shrunken neurons with dense cytoplasm and irregular membrane boundaries were frequently observed in the faecal peritonitis group, while such neurons were not discerned in un-operated and sham-operated control groups (Fig. 2A-E). Shrunken dark neurons were also found within frontal cortex in septic animals. These abnormal and pyknotic neuronal cells were not included in morphometric analyses. In addition, neuroglial cells appeared to be more prevalent in the faecal peritonitis group (Fig. 2F-G) and 

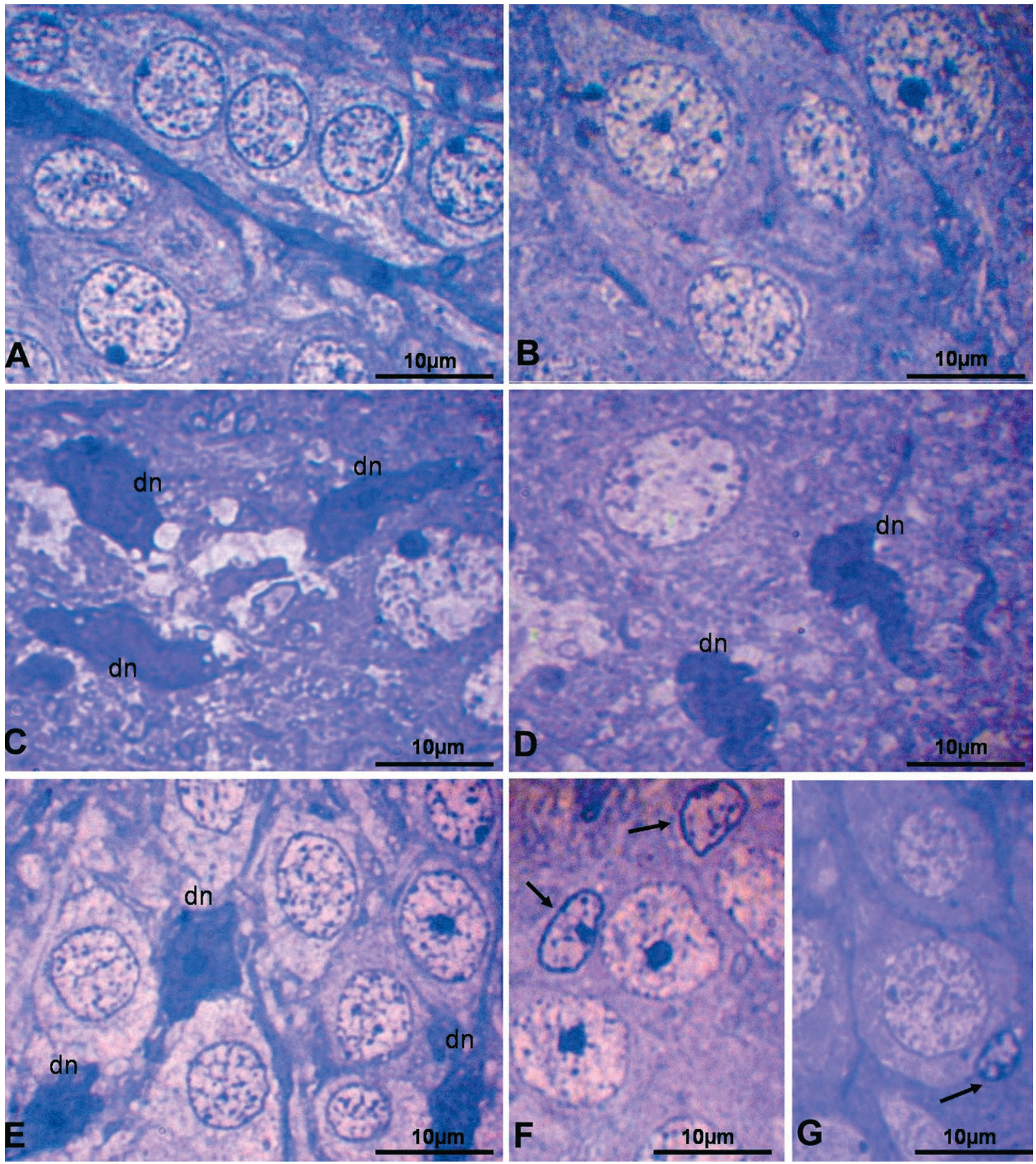

Fig. 2. Photomicrographs of neurons from CA1 (A and C) and CA3 (B and D) areas of sham-operated control (A, B) and faecal peritonitis (C, D) groups. Neurons with dark and dense appearances at the cytoplasm and nuclear areas, irregular membrane boundaries, shrunken cytoplasms and triangular shapes (dn) were observed at CA1 (C), CA3 (D) and DG areas (E) in faecal peritonitis group, whereas healthy neurons were observed in CA1 (A) and CA3 (B) regions of sham-operated. Neuroglial cells (ng) appeared to be more prevalent in the faecal peritonitis group's hippocampal areas (F and G). Scale bars " $10 \mathrm{~mm}$ ". 


\section{Volume densities of neurons}

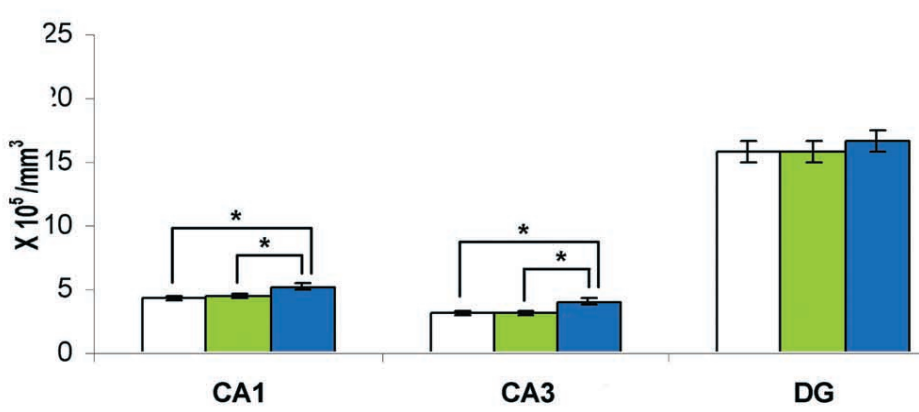

Mean nuclear diameters

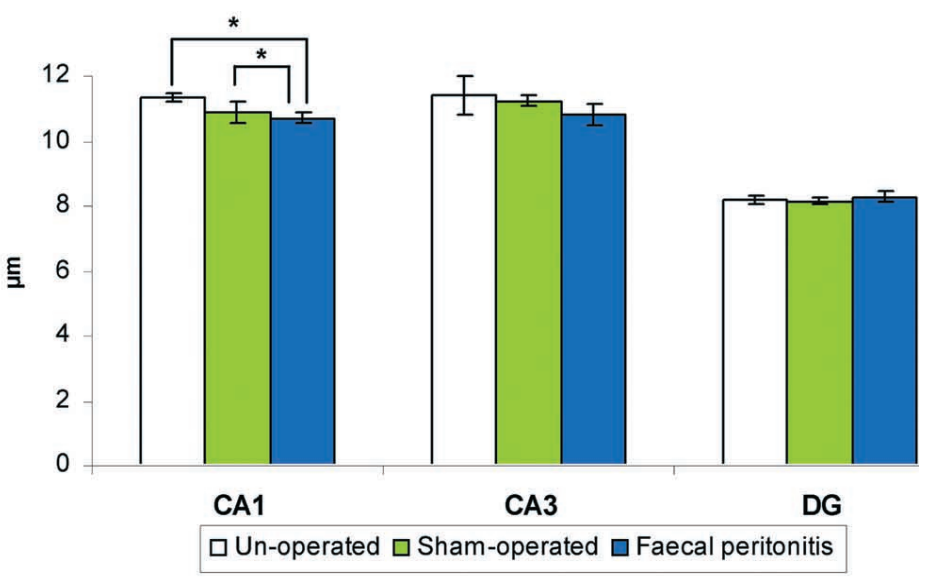

Fig.3. Bar diagrams of the volume densities of neurons and mean nuclear diameters. $* \mathrm{p}<0.05$. located in the vicinity of healthy looking neuronal somas instead of capillaries or dark neurons on examined areas of hippocampus.

The mean volume densities and mean nuclear diameters of pyramidal neurons in the CA1, CA3 and granular neurons in DG of the three groups investigated are given in Table I. Pyramidal neuron volume density was significantly higher in CA1 area of the faecal peritonitis group compared to both unoperated $(p<0.05)$ and sham-operated $(p<0.05)$ control groups, while no significant difference was present between the two control groups $(p>0.05)$ (Fig. 3). Pyramidal neuron volume density was also significantly higher in CA3 area of the faecal peritonitis group compared to both un-operated $(p<0.05)$ and sham-operated $(p<0.05)$ control groups, while no significant difference was present between the two control groups $(p>0.05)$ (Fig. 3). However, there was no significant difference of neuronal volume density in the DG granular neurons between three groups investigated $(p>0.05)$. Mean nuclear diameter of pyramidal neurons in CA1 area of the faecal peritonitis group was significantly lower compared to both un-operated and sham-operated control groups $(p<0.05)$. There was no significant difference between the mean nuclear diameters of pyramidal neurons in CA3 and granular neurons in DG in the three groups investigated (Fig. 3).

Table I. Volume densities and Mean nuclear diameters of neurons.

\begin{tabular}{|c|c|c|c|c|c|c|}
\hline & & \multirow{2}{*}{ Un-operated group } & \multirow{2}{*}{ Sham-operated group } & \multirow{2}{*}{$\begin{array}{l}\text { Faecal Peritonitis } \\
\text { group }\end{array}$} & \multicolumn{2}{|c|}{$\begin{array}{c}\text { \% Changes in Faecal } \\
\text { Peritonitis group }\end{array}$} \\
\hline & & & & & $U n-O p$ & Sham-Op \\
\hline \multirow{2}{*}{ CA1 } & $\begin{array}{l}\text { Volume } \\
\text { Density }\end{array}$ & $440809 \pm 16155$ & $453868 \pm 19286 \#$ & $524704 \pm 27872 *$ & $119 \%$ & $116 \%$ \\
\hline & $\begin{array}{c}\text { Mean } \\
\text { Nuclear } \\
\text { Diameter }\end{array}$ & $11.35 \pm 0.18$ & $11.19 \pm 0.33$ & $10.12 \pm 0.16^{* *}$ & $89 \% * *$ & $90 \%$ \\
\hline \multirow{2}{*}{ CA3 } & $\begin{array}{l}\text { Volume } \\
\text { Density }\end{array}$ & $313026 \pm 18299$ & $317480 \pm 18168 \#$ & $403006 \pm 23102 * *$ & $128 \%$ & $127 \%$ \\
\hline & $\begin{array}{c}\text { Mean } \\
\text { Nuclear } \\
\text { Diameter }\end{array}$ & $11.42 \pm 0.57$ & $11.23 \pm 0.95$ & $10.82 \pm 0.30$ & $95 \%$ & $96 \%$ \\
\hline \multirow{2}{*}{ DG } & $\begin{array}{l}\text { Volume } \\
\text { Density }\end{array}$ & $1579812 \pm 81957$ & $1587944 \pm 82735 \#$ & $1663864 \pm 88333 \#$ & $105 \%$ & $105 \%$ \\
\hline & $\begin{array}{c}\text { Mean } \\
\text { Nuclear } \\
\text { Diameter }\end{array}$ & $8.22 \pm 0.13$ & $8.14 \pm 0.10$ & $8.28 \pm 0.15$ & $101 \%$ & $101 \%$ \\
\hline
\end{tabular}

Volume densities $/ \mathrm{mm}^{3}$ and mean nuclear diameters $(\mu \mathrm{m})$ of neurons are given as mean \pm SEM. "\% Changes" represents percentile changes in faecal peritonitis group compared to un-operated (un-op) and sham-operated (sham-op) control groups respectively (*, $\mathrm{p}<0.05 ; * *, \mathrm{p}<0.01 ; \#, \mathrm{p}>0.05)$. 


\section{DISCUSSION}

It is well known that the major problems of ICU (Intensive care unit) survivors from sepsis are memory impairment, depressive-like symptoms and anxiety-like behavior (Streck et al., 2008). However, long or short term involvement of the brain in sepsis and underlying mechanisms of SAE is not completely understood. The mechanism proposed in the pathogenesis of SAE involves; microorganisms directly invading the CNS or affecting it with their toxins, metabolic alterations that could adversely affect CNS function, breakdown of blood brain barrier, altered neurotransmitter synthesis and receptorial distribution, impairment of brain circulation and auto regulatory power (Streck et al.). However, despite the importance of hippocampus in learning, memory and cognitive deficits, little information is available about the integrity of hippocampal neurons in sepsis. Thus, we have investigated the effects of sepsis onto the hippocampal morphology in a rat model of intraperitoneal sepsis induced by experimental faecal peritonitis and our results revealed a significantly higher neuronal density in together with widespread dark, shrunken neurons with dense cytoplasm and irregular membrane boundaries CA1 and CA3 areas of faecal peritonitis group compared to the sham and unoperated groups. One possible explanation for the higher neuronal density in these regions would be the decreased neuronal cell volumes that would cause a more condensed alignment of neurons within these areas, therefore significantly lower nuclear diameter of healthy looking pyramidal neurons of CA1 area would contribute to this apparent increase of neuronal density in that particular area.

Increased synaptic density in CA1 and CA 3 regions may also be explained as an attempt to compensate for a possible loss in synaptic terminals due to the cardiovascular collapse, since synapse loss may usually precedes neuronal loss in neurodegenerative processes. The hippocampus is well positioned to receive soluble ligands from blood or cerebro-spinal fluid, lying alongside the choroid plexus with its rich blood supply and immediately adjacent to the cerebral ventricles (Lathe, 2001). Thus, this region is might be more vulnerable for the cytotoxic and neurodegenerative effects of sepsis (Semmler et al., 2005). It is known that the sepsis reduces the number of perfused capillaries, thereby impacting on oxygen diffusion to mitochondria with varied microvascular response such as a decrease in cross sectional area of capillaries, increased blood viscosity, increased leukocyte adhesion to endothelial cells. These would then lead to an increased resistance to blood flow (Bauer, 2002) and a possible cerebral hypoperfusion that might induce neuronal degeneration or impaired synaptic activity. More precise ultrastructural stereological studies would be required to confirm this possibility.

Although, it is well established that the CA1 area (Sommer's sector) is known to be especially vulnerable to hypoxia (Fix, 2001), the results of the present study suggests that the significantly reduced $(81 \%)$ blood flow was not sufficient to develop an apparent neuronal death in this particular model of sepsis. This assumption would be supported by the fact that decrease as high as $62 \%$ in the brain blood flow in human sepsis appears to be insufficient to threaten neuronal death and SAE may arise prior to cerebral hypoperfusion (Papadopoulos et al., 2000). Furthermore, it has been suggested that the cerebral blood flow needs to drop to $45 \%$ before the electroencephalogram is affected and to $33 \%$ for anoxic depolarization (Papadopoulos et al., 2000). It has been previously reported that the hypoxicischemic injury can induce the cell death via necrosis, programmed cell death or alternatively neither apoptotic nor necrotic cell death mechanisms (Sheldon et al., 2001; Cho \& Toledo-Pereyra, 2008; Doyle et al., 2008). Increased neuronal density observed in hypocampal regions in the present study suggests that cardiovascular collapse developed in the present study may not be sufficient to cause hypoxic-ischemic injury that would lead to a discernable neuronal degeneration at least at the early stages. However, it's tempting to suggest that the dark, shrunken neurons frequently observed in these regions in the present study may represent an early stage of a neuronal degeneration. These, shrunken and dark neurons are unlikely to be an artifact since such neurons were not evident in shamoperated controls which similar experimental procedures were performed. They were also not confined to the hippocampus and observed in various cortical regions suggesting that they are not region-specific. The presence of such neurons have also been reported previously in different brain areas including hippocampus after the CLP procedure on rats (Messaris et al., 2004) and frontal cortex of septic pigs (Papadopoulos et al., 1999). These types of neurons are also reported to appear in brain after ischemia, trauma and various other insults (Gallyas et al., 1992). Although, the pathophysiological basis of these changes (shrunken size with slightly condensed chromatin) is not entirely described they may be regarded as an early sign of programmed cell death (Ito et al., 2007). There is compelling evidence to support this assumption. Increased apoptosis is reported in neurons of CA1 regions of the hippocampus, in choroid plexus and in purkinje cells of the cerebellum in CLP model of sepsis (Messaris et al.), in the cortex, hippocampus, midbrain and cerebellum in LPS 
model of sepsis (Semmler et al., 2005) and in the autonomic nuclei (Sharshar et al., 2003) of septic patients. Furthermore, some, but not all, dark neurons were shown to be positive for TUNEL or Hoechst 33342 staining, indicating that they are apoptotic in an aged presenilin-1 mutant mice model (Nishioku et al., 2009). Although the morphological criteria such as chromatin condensation, nuclear and cell shrinkage and maintained plasma membrane integrity suggests that dark, atrophic neurons observed in the current study are apoptotic, additional investigations using different markers for apoptosis in this model will be necessary to confirm that these dark cells are apoptotic.

Glial response seems to be another important enigma of SAE. Astrocytes play a protective role in regulating local blood flow, transporting energy substrates from microvessels to neurones, preserving BBB properties, destroying pathogens, removing debris and promoting tissue repair. However, activated glial cells acquire neurotoxic properties, notably by releasing nitric oxide (NO) and glutamate, in circumstances that include cerebral trauma, inflammation and infection. Nishioku et al. reported microglial activation and detachment of pericytes in hippocampus in LPS model of mouse. Semmler et al. reported increased number of ED1-reactive microglial cells mostly located in close vicinity to brain blood vessels in LPS-treated animals rats (Semmler et al., 2008). In contrast, neuroglial cells which were more prevalent in the faecal peritonitis group, appeared to be located in the vicinity of healthy looking neuronal somas without any apparent coexistence with capillaries or dark neurons on examined areas of hippocampus. In agreement with our findings, activated microglial cells diffusely distributed throughout the parenchyma has recently been reported in a case-control study of 13 patients who died with sepsis (Lemstra et al., 2007). The difference between these studies may possibly reflect the differences of the models used or different stages of microglial activation.

In the present study, the effects of sepsis onto the hippocampal morphology have been investigated in a rat model of intraperitoneal sepsis that is induced by experimental faecal peritonitis. Necessity of a uniform and valid definition of sepsis applicable to both small and large animals has previously been highlighted, and its importance in preclinical sepsis studies underscored (Parker \& Watkins, 2001). Endotoxemia and bacteremia models have widely been used since they reproduce many characteristics of sepsis and are highly controlled and standardized. However, doubts over the clinical relevance of these models have been pointed out (Wichterman et al., 1980) since they reflect a primarily systemic challenge and create neither an infectious focus nor the protracted immune reaction that characterizes sepsis. Thus, compared to mechanisms such as endotoxicosis and intravenous bacterial infusion, peritonitis models have been proposed as the 'gold standard' in case of appropriate usage of virulent bacterial species (Parker \& Watkins; Fink \& Heard, 1990). Although, peritonitis models developed in pigs (Doods, 1982) and primates (Kinasewitz et al., 2000) are those that most closely simulate the clinical situation encountered in humans (Parker \& Watkins), recent changes in attitude towards the use of such large animals have significantly limited their use, and small mammals have often been preferred as inexpensive, available, genetically similar and pathogen-free alternatives. Peritonitis may be induced in rodents in several ways such as perforation of the bowel, inoculums of faecal material or pure bacteria cultures and caecal ligation and puncture (Parker \& Watkins). Previous studies suggested that peritonitis models that have used pooled faecal material produce a physiological response in most species similar to that found in humans (Nichols et al., 1978; Wichterman et al.; Lang et al., 1983, 1984; Parker \& Watkins). It has also been reported that the gastrointestinal content of animals vary between species (Browne \& Leslie, 1976), and animals appeared to be tolerant to their own faecal flora (King et al., 1975). Thus, we preferred to use a common pool of faecal inoculums (Lang et al., 1983; 1984) to induce sepsis, instead of caecal ligation and puncture in the present study. Furthermore, in our previous studies with faecal peritonitis rat model, we have effectively monitored the hemodynamic parameters, which have reflected adequate simulation of sepsis and septic shock (Ari et al.; Kafa et al.).

Since encephalopathy may develop in sepsis without adequately settled down hypoxia and also occurs without electroencephalographic changes (Papadopoulos et al., 2000), those neuronal morphological alterations that were triggered by faecal inoculum procedure may be represent the early effects of sepsis on brain parenchyma. Careful observation of vital parameters and examination of blood cultures may offer significant proofs compared to electroencephalographic recordings or inspection of mental states when animals undergo anesthesia for surgery and monitorization procedures. We have monitored sham-operated control and faecal peritonitis groups for $4 \mathrm{~h}$, control values were also obtained from un-operated control group. In addition to the apparent drop in the blood pressure and rectal temperature, increased heart rate and marked respiratory failure observed in the current study supported the feasibility of our model. Although septic conditions may have large spectrum of etiology and faecal peritonitis may not necessarily be the sole culprit of the septic condition from etiopathological aspect (Eiderman et al., 1996), the vital parameters suggest the model used in the present study appears to represent a suitable one for the study of septic encephalopathy on morphological levels. 
Together, the results of the present study highlight the complexity of the changes and the early impairment of neuronal/glial metabolism and activity during SE. To this end, it is tempting to investigate the synaptic integrity of these neurons, which would be effected as an early sign of neuronal degeneration and shed further light on the understanding of the neurobiological changes observed in SAE. It should also bear in mind that the removal of the brains $4 \mathrm{hr}$ after the induction of sepsis would be insufficient to observe possible effects of cerebral hypoperfusion and other potential factors such as local generation of inflammatory molecules by peripheral immune cells or perimicrovascular oedema that would induce cell death.

KAFA, I. M.; ARI, I. \& KURT, M. A. Investigación morfométrica de neuronas en las areas hipocampales CA1, CA3 y giro dentado en un modelo de sepsis en rata. Int. J. Morphol., 28(1):183-192, 2010.

RESUMEN: Aproximadamente, la mitad de los pacientes con sepsis progresiva desarrollan encefalopatía, pero hay escaso conocimiento en cuestión de como la sepsis asociada con encefalopatía contribuye a la disfunción cerebral. El hipocampo es una de las regiones más vulnerables durante la sepsis experimental. En el presente estudio, fueron analizados los efectos de la sepsis sobre la densidad neuronal y la morfología en las áreas CA1, CA3 y giro dentado en un modelo de sepsis intraperitoneal en rata. Veinticuatro ratas Wistar se dividieron en tres grupos diferentes: grupo de peritonitis fecal, operación simulada y control no operado. La densidad del volúmen piramidal fue significativamente mayor en el área CA1 del grupo con peritonitis fecal en comparación con los grupos no operados $(\mathrm{p}<0,05)$ y la operación simulada $(\mathrm{p}<0,05)$. La densidad de volumen de las neuronas piramidales fue significativamente mayor en el área CA3 del grupo peritonitis fecal en comparación con los no operado $(\mathrm{p}<0,05)$ y la operación simulada ( $<<0,05)$. El diámetro promedio nuclear de las neuronas piramidales en la zona CA1 del grupo de peritonitis fecal fue significativamente menor $(\mathrm{p}<0,05)$ en comparación con el grupo de control no operado. Las neuronas fueron observadas con frecuencia reducidas y las células neurogliales parecen ser frecuentes en el grupo de peritonitis fecal en comparación con grupos de control. Estos resultados en conjunto sugieren que la sepsis intraperitoneal no inicia la muerte celular en las primeras etapas de la sepsis, aunque los signos morfológicos de la neurodegeneración empiezan a aparecer.

PALABRAS CLAVE: Sepsis: Modelos de sepsis animal; Peritonitis fecal; Hipocampo; Sepsis asociada a encefalopatía.

\section{REFERENCES}

American College of Chest Physicians/Society of Critical Care Medicine Consensus Conference. American College of Chest Physicians/Society of Critical Care Medicine Consensus Conference: definitions for sepsis and organ failure and guidelines for the use of innovative therapies in sepsis. Crit. Care Med., 20(6):864-74, 1992.

Ari, I.; Kafa, I. M. \& Kurt, M. A. Perimicrovascular oedema in the frontal cortex in a rat model of intraperitoneal sepsis. Exp. Neurol., 198(1):242-9, 2006.

Basler, T.; Meier-Helman, A.; Brele, D. \& Reinhart, K. Amino acid imbalance early in septic encephalopathy. Intensive Care Med., 28(3):293-8, 2002.

Bauer, P. R. Microvascular responses to sepsis: clinical significance. Pathophysiology, 8(3):141-8, 2002.

Bochud, P. Y. \& Calandra, T. Pathogenesis of sepsis: new concepts and implications for future treatment. Br. Med. J. 326(7383):262-6, 2003.

Bogdanski, R.; Blobner, M.; Hanel, F. \& Kochs, J. Septic Encephalopathy. Anasthesiol. Intensivmed. Notfallmed
Schmerzther, 34(3):123-30, 1999.

Bone, R. C. Towards an epidemiology and natural history of SIRS (Systemic inflammatory response syndrome). JAMA, 268(24):3452-5, 1992.

Bradley, J. R.; Wilks, D. \& Rubinstein, D. The vascular endothelium in septic shock. J. Infect., 28(1):1-10, 1994.

Browne, M. K. \& Leslie, G. B. Animal models of peritonitis. Surg. Gynecol. Obstet., 143(5):738-40, 1976.

Cho, B. B. \& Toledo-Pereyra, L. H. Caspase-independent programmed cell death following ischemic stroke. $J$. Invest. Surg., 21(3):141-7, 2008.

Clawson, C. C.; Hartmann, J. F. \& Vernier, R. L. Electron microscopy of the effect of gram negative endotoxin on the blood brain barrier. J. Comp. Neurol., 127(2):183-98, 1966.

Davies, D. C. Blood brain barrier breakdown in septic encephalopathy and brain tumours. J. Anat., 200(6):639-46, 2002. 
Deng, X.; Wnag, X. \& Andersson, R. Endothelial barrier resistance in multiple organs after septic and nonseptic challenges in the rat. J. Appl. Physiol., 78(6):2052-61, 1995.

Doods, W. J. The pig model for biomedical research. Fed. Proc., 41(2):292-7, 1982.

Doyle, K. P.; Simon, R. P. \& Stenzel-Poore, M. P. Mechanisms of ischemic brain damage. Neuropharmacology, 55(3):310-8, 2008.

Eggers, V.; Schilling, A.; Kox, W. J. \& Spies, C. Septic encephalopathy. Diagnosis and therapy. Anaesthesist, 52(4):294-303, 2003.

Eiderman, L. A.; Putterman, D.; Putterman, C. \& Sprung, C. L. The spectrum of septic encephalopathy. Definitions, etiologies, and mortalities. J. Am. Med. Assoc., 275(6):470-3, 1996.

Esen, F.; Erdem, T.; Aktan, D.; Orhan, M.; Kaya, M.; Eraksoy, H.; Cakar, N. \& Telci, F. Effect of magnesium sulfate administration on blood-brain barrier in a rat model of intraperitoneal sepsis: A randomized controlled experimental study. Critical Care, 9(1):1823, 2005.

Fink, M. P. \& Heard, S. O. Laboratory models of sepsis and septic shock. J. Surg. Res., 49(2):186-96, 1990.

Fix, J. D. Neuroanatomy. $3^{\text {rd }}$ Ed. Phidelphia, Lippincott Williams \& Wilkins, 2001.

Gallyas, F.; Zoltay, G. \& Dames, W. Formation of "dark" (argyrophilic) neurons of various origin proceeds with a common mechanism of biophysical nature (a novel hypothesis). Acta Neuropathol., 83(5):504-9, 1992.

Ito, U.; Nagasao, J.; Kawakami, E. \& Oyanagi, K. Fate of disseminated dead neurons in the cortical ischemic penumbra: ultrastructure indicating a novel scavenger mechanism of microglia and astrocytes. Stroke, 38(9):2577-83, 2007.

Jeppson, B.; Freund, H. R.; Gimmon, Z.; James, J. H.; von Meyenfeldt, M. F. \& Fischer, J. E. Blood brain barier dearangement in sepsis: cause of septic encephalopathy? Am. J. Surg., 141(1):136-41, 1981.

Kafa, I. M.; Ari, I. \& Kurt, M. A. The peri-microvascular edema in hippocampal CA1 area in a rat model of sepsis. Neuropathology, 27(3):213-20, 2007.
Kinasewitz, G. T.; Chang, A. C. K.; Peer, G. T.; Hinshaw, L. B. \& Taylor, F. B. Peritonitis in the baboon: A primate model which simulates human sepsis. Shock, 13(2):100-9, 2000.

King, D. W.; Gurry, J. F.; Ellis, Pegler, R. B. \& Brooke, B. N. A rabbit model of perforated appendicitis with peritonitis. Br. J. Surg., 62(8):642-4, 1975.

Lang, C. H.; Bagby, G. J.; Bornside, G. H.; Vial, L. J. \& Spitzer, J. J. Sustained hypermetabolic sepsis in rats: Characterization of the model. J. Surg. Res., 35(3):20110, 1983.

Lang, C. H.; Bagby, G. J.; Ferguson, J. L. \& Spitzer, J. J. Cardiac output and redistribution of organ blood flow in hypermetabolic sepsis. Am. J. Physiol., 246(3):3317, 1984.

Lathe, R. Hormones and the hippocampus. J. Endocrinol., 169(2):205-31, 2001.

Lemstra, A. W.; Groen, in't Woud, J. C.; Hoozemans, J. J.; van Haastert, E. S.; Rozemuller, A. J.; Eikelenboom, P. $\&$ van Gool, W. A. Microglia activation in sepsis: a casecontrol study. J. Neuroinflammation, 15, 4:4, 2007.

Ling, E. A.; Paterson, J. A. Privat, A.; Mori, S. \& Leblond, C. P. Investigation of glial cells in semithin sections: I. Identification of glial cells in the brain of young rats. $J$. Comp. Neurol., 149(1):43-71, 1973.

Messaris, E.; Memos, N.; Chatzigianni, E.; Konstadoulakis, M. M.; Menenakos, E.; Katsaragakis, S.; Voumvourakis, C. \& Androulakis, G. Time-dependent mitochondrial-mediated programmed neuronal cell death prolongs survival in sepsis. Crit. Care Med., 32(8):1764-1770, 2004.

Miki, T.; Fukui, Y.; Itoh, M.; Hisano, S.; Xie, Q. \& Takeuchi, Y. Estimation of the numerical densities of neurons and synapses in cerebral cortex. Brain Res. Protoc., 2(1):916, 1997.

Moulin, G. C.; Paterson, D.; Hedley-Whyte, J \& Broitman, S. A. E. coli peritonitis and bacteremia cause increased blood-brain permeability. Brain Res., 340(2):261-8, 1985.

Nichols, R. L.; Smith, J. W. \& Balthazar, E. R. Peritonitis and intraabdominal absess: An experimental model for the evaluation of human disease. J. Surg. Res., 25(2):129-34, 1978. 
Nishioku, T.; Dohgu, S.; Takata, F.; Eto, T.; Ishikawa, N.; Kodama, K. B.; Nakagawa, S.; Yamauchi, A.; Kataoka, Y. Detachment of Brain Pericytes from the Basal Lamina is Involved in Disruption of the Blood-Brain Barrier Caused by Lipopolysaccharide-Induced Sepsis in Mice. Cell Mol. Neurobiol., 29(3):309-316, 2009.

Papadopoulos, M. C.; Davies, D. C.; Moss, R. F.; Tighe, D. \& Bennett, E. D. Pathophysiology of septic encephalopathy: A review. Crit. Care Med., 28(8):3019-24, 2000.

Papadopoulos, M. C.; Lamb, F. J.; Moss, R. F.; Davies, D. C.; Tighe, D. \& Bennet, E. D. Faecal peritonitis causes oedema and neuronal injury in pig cerebral cortex. Clin. Sci., 96(5):461-6, 1999.

Parker, S. J. \& Watkins, P. E. Experimental models of gramnegative sepsis. Br. J. Surg., 88(1):22-30, 2001.

Parrillo, J. E.; Parker, M. M; Natanson, C.; Suffredini, A. F; Danner, R. L.; Cunnion, R. E. \& Ognibene, F. P. Septic shock in humans. Advances in the understanding of pathogenesis, cardiovascular dysfunction, and therapy. Ann. Intern. Med. 113(3):227-42, 1990.

Semmler, A.; Hermann, S.; Mormann, F.; Weberpals, M.; Paxian, S. A.; Okulla, T.; Schäfers, M.; Kummer, M. P.; Klockgether, T. \& Heneka, M. T. Sepsis causes neuroinflammation and concomitant decrease of cerebral metabolism. J. Neuroinflammation, 5:38, 2008.

Semmler, A.; Okkula, T.; Sastre, M.; Dumitrescu-Ozimek, L. \& Heneka, M. T. Systemic inflammation induces apoptosis with variable vulnerability of different brain regions. J. Chem. Neuroanat., 30(2-3):144-57, 2005.

Sharshar, T.; Gray, F.; Lorin, de la Grandmaison, G.; Hopkinson, N. S.; Ross, E.; Dorandeu, A.; Orlikowski, D.; Raphael, J. C.; Gajdos, P. \& Annane, D. Apoptosis of neurons in cardiovascular autonomic centres triggered by inducible nitric oxide synthase after death from septic shock. Lancet, 362(9398):1799-805, 2003.

Sheldon, R. A.; Hall, J. J.; Noble, L. J. \& Ferriero, D. M. Delayed cell death in neonatal mouse hippocampus from hypoxia-ischemia is neither apoptotic nor necrotic. Neurosci. Lett., 304(3):165-8, 2001.

Streck, E. L.; Comim, C. M.; Barichello, T. \& Quevedo, J. The septic brain. Neurochem. Res., 33(11):2171-7, 2008.
Tsao, N.; Hsu, H. P.; Wu, C. P.; Liu, C. C. \& Lei, H. Y. Tumour necrosis factor-a causes an increase in bloodbrain barrier permeability during sepsis. J. Med. Microbiol., 50(9):812-21, 2001.

Voyce, S. J. \& Becker, R. C. Adaptive and maladaptive cardiovascular responses in human sepsis. Am. Heart J., 122(5):1441-8, 1991.

Wichterman, K. A.; Baue, A. E. \& Chaudry, I. H. Sepsis and septic shock-- a review of laboratory models and a proposal. J. Surg. Res., 29(2):189-201, 1980.

Wilson, J. X. \& Young, G. B. Progress in clinical neurosciences: sepsis-associated encephalopathy: evolving concepts. Can. J. Neurol. Sci., 30(2):98-105, 2003.

Correspondence to:

Ilker Mustafa Kafa, M.D.

Uludag University, Faculty of Medicine

Anatomy Department, Gorukle

16059, Bursa

TURKEY

Tel: +902242955316

Fax: +90224 4417535 )

Email: imkafa@uludag.edu.tr

Received: 11-08-2009

Accepted: 04-12-2009 